\title{
CARDIOVASCULAR EPIDEMIOLOGY
}

\section{Endothelial function and outdoor temperature}

\author{
Tim S. Nawrot ${ }^{1, *}$, Jan A. Staessen ${ }^{1}$, Robert H. Fagard ${ }^{1}$, Luc M. Van Bortel ${ }^{2} \&$ Harry A. \\ Struijker-Boudier ${ }^{3}$ \\ ${ }^{1}$ Study Coordinating Centre, Laboratory of Hypertension, Department of Molecular and Cardiovascular Research, University \\ of Leuven, Leuven; ${ }^{2}$ Heymans Institute of Pharmacology, Ghent University, Gent, Belgium; ${ }^{3}$ Department of Pharmacology and \\ Toxicology, Cardiovascular Research Institute Maastricht, University of Maastricht, The Netherlands
}

Accepted in revised form 24 January 2005

\begin{abstract}
Studies within populations consistently showed that cardiovascular mortality increases with hot weather. However, the biological mechanisms underlying this association remain largely unknown. Endothelial function plays a pivotal role in the pathogenesis of cardiovascular disease. Therefore, we investigated the association between endothelial function and outdoor temperature. We measured flow-mediated vasodilatation (FMD) as index of endothelial function in 274 randomly recruited subjects $(50 \%$ women, mean age 40.6 year). Both before
\end{abstract}

(partial $r=-0.14, p=0.017$ ) and after adjustment (partial $r=-0.17, p=0.006$ ) for sex, age, body mass index, brachial artery diameter and current smoking, FMD was negatively associated with mean daily temperature. The odds of endothelial dysfunction increased by $58 \%$ (95\% CI: $4-141 \% ; p=0.03)$ for each $10{ }^{\circ} \mathrm{C}$ increment in mean daily temperature during the week before the examination. Our findings suggest that endothelial dysfunction might contribute to the increase in cardiovascular morbidity and mortality associated with hot weather.

Key words: Cardiovascular mortality, Endothelium, Epidemiology, Heat waves, Outdoor temperature, Vasodilation

\section{Introduction}

In the summer of 2003, France experienced the longest heat wave ever recorded in history with maximum daily temperatures exceeding $40{ }^{\circ} \mathrm{C}$ in July and August. Morgues and funeral parlours were unable to cope with the increased workload. Health care officials estimated that the mortality attributable to the record high temperatures exceeded 15,000 deaths. In general, during heat waves, morbidity and mortality from cardiovascular disorders rises [1-4]. The relentless build-up of greenhouse gases is likely to continue. In the future, global warming will more frequently cause extreme weather patterns [5]. The cause underlying the association between cardiovascular disease and hot weather therefore needs to be elucidated.

The endothelium plays a pivotal role in the pathogenesis of cardiovascular disease [6-7]. Brachial artery flow-mediated dilation (FMD) serves as a measure of endothelial vasodilator function in humans [8]. Vasodilation of the brachial artery, after a short lasting ischaemia of the distal forearm, is due to the release of nitric oxide from endothelial cells in response to the increased shear stress. This physiological response allows the non-invasive assessment of endothelial function.[9] Experimental and clinical studies suggest that development of endothelial dysfunction, including reduced nitric bioavailability, contributes to atherosclerosis and pathogenesis of cardiovascular disease [7]. Human studies demonstrate that endothelial dysfunction precedes the development of clinically apparent atherosclerosis in individuals with cardiovascular risk factors such as hypertension, [10] and obesity [11]. In the present study, we determine whether endothelial function is related to outdoor temperature.

\section{Materials and methods}

From March 2002 to March 2003, we assessed endothelial function in 274 subjects (50\% women) with mean age (SD) of 40.6 (15.7) years, who were randomly recruited (participation rate $80 \%$ ) from the population of a geographically defined area within the framework of the Flemish Study on Environment, $G$ enes and Health Outcomes (FLEMENGHO). The Ethics Committee of the University of Leuven approved the protocol and the study was performed in accordance with the Helsinki Declaration. The Royal Meteorological Institute (Brussels, Belgium) provided mean and maximal daily temperatures of the study region (Kleine Brogel) over the study period, which 
averaged 11.2 (SD 6.6) and $16.2(7.9){ }^{\circ} \mathrm{C}$, respectively, with ranges from -4.9 to $28.9{ }^{\circ} \mathrm{C}$ and from -2.7 to $36.2{ }^{\circ} \mathrm{C}$, respectively.

We studied endothelial function in an air-conditioned room where temperature averaged $22.9(0.58)$ ${ }^{\circ} \mathrm{C}$ (range $21.8^{8}-24.0^{\circ} \mathrm{C}$ ). After the subjects had rested for $20 \mathrm{~min}$ in the supine position, we measured the diameter of the brachial artery $8 \mathrm{~cm}$ above the elbow of the right arm, using a wall tracking ultrasound system with a $7.5 \mathrm{MHz}$ linear array transducer mounted on a fixed support. Baseline values were the averages of four measurement periods each consisting of five to six cardiac cycles. We inflated an occluding cuff for $4.5 \mathrm{~min}$ to $220 \mathrm{mmHg}$ to induce ischaemia of the forearm distal to the location of the transducer. During $5 \mathrm{~min}$ after the release of the occluding pressure, we remeasured the brachial artery diameter at 15 -sec intervals during $3 \mathrm{~min}$ and thereafter at 30 -sec intervals for a further $2 \mathrm{~min}$. We expressed FMD as the percentage diameter change of the brachial artery relative to baseline. In a pilot study $(\mathrm{n}=10)$, the reproducibility was assessed in 10 individuals. The intra-observer intersession coefficients were $2.7 \%( \pm 0.5)$ for diameter and $16.7 \%$ $( \pm 2.5)$ for FMD.

We used SAS software version 8.1 (SAS Institute Inc, Cary, NC). For comparison of means, medians and proportions we applied Student's $t$-test, Wilcoxon's test and the $\chi^{2}$-statistic, respectively. The other statistical methods included single and multiple linear regression. We applied multiple logistic regression analysis to study the relation between endothelial dysfunction and outdoor temperature. Models were constructed based on parameters known to be biologically associated with endothelial function. Other variables, included in the multiple linear regression and logistic models were body-mass index, smoking, and baseline brachial artery diameter. We assessed the linearity assumption by plotting endothelial function vs. the quartiles of outdoor temperature. The linear and quadratic terms of age and outdoor temperature were tested and if significant they were included in the model.

\section{Results}

The characteristics of the 274 study participants are listed in Table 1 . Seventy two subjects $(26.3 \%)$ were smokers. FMD averaged (SD) 7.2 (4.6) \%. Figure 1 depicts that FMD declined with advancing age. Stepwise regression including sex, age, body-mass index, total cholesterol, HDL cholesterol, systolic and diastolic blood pressure showed that sex and age were significant determinants of FMD, explaining $3 \%(p=0.0005)$ and $15 \%(p<0.0001)$ of its variance, respectively. Independent of sex and age, FMD was inversely correlated with baseline brachial diameter (partial $r=-0.21 ; p=0.0005$ ). Additional
Table 1. Characteristics of the study population

\begin{tabular}{lrccc}
\hline Characteristics & \multicolumn{1}{l}{ Men } & Women & \multicolumn{1}{l}{$p$} \\
\hline Age, years & $41.1(15.0)$ & $40.1(16.3)$ & 0.61 \\
Systolic BP, mmHg & $112.7(11.5)$ & $115.1(13.4)$ & $<0.0001$ \\
Diastolic BP, mmHg & 73.1 & $(9.7)$ & $71.5(9.3)$ & 0.16 \\
BMI, kg/m 2 & 26.1 & $(3.8)$ & $25.0(4.9)$ & 0.03 \\
Total cholesterol, mmol & $5.55(1.13)$ & $5.54(1.18)$ & 0.11 \\
HDL cholesterol, mmol & $1.25(0.27)$ & $1.82(0.42)$ & 0.0001 \\
\hline
\end{tabular}

Data presented are means (SD).

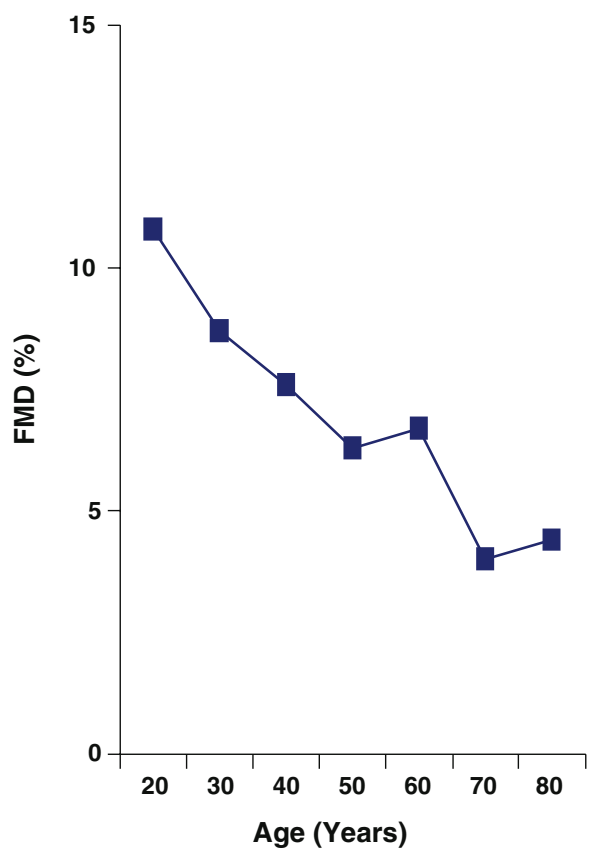

Figure 1. Flow mediated vasodilatation during ageing. Data are as means for age classes.

to these significant predictors, body-mass index and smoking status were forced in the future adjusted models.

After adjustment for sex, age, body mass index, brachial artery diameter at baseline and smoking, FMD decreased with the mean daily temperature on the examination day (partial $r=-0.17 ; p=0.006$ ). These findings were consistent when we averaged the mean daily temperatures for up to 3 weeks before the examination (Table 2). Maximal daily temperature ranged from -2.7 to $36.2{ }^{\circ} \mathrm{C}$. FMD decreased, from the lowest to the highest quartile of maximal outdoor temperature at the day of the measurement from 8.2 to $6.6 \%(p=0.03$; Figure 2$)$.

A FMD less than 7\% may reflect endothelial dysfunction [9]. Logistic regression with adjustments as before revealed that the odds of having endothelial dysfunction increased by $41 \%$ (95\% CI: $1-98 \%$; $p=0.05$ ) for each $10{ }^{\circ} \mathrm{C}$ increment in the mean daily temperature on the examination day. For the mean daily temperatures averaged over 1 week before the 
Table 2. Associations between flow mediated vasodilation and outdoor temperature

\begin{tabular}{lll}
\hline Temperature $\left({ }^{\circ} \mathrm{C}\right)$ & Partial $r^{*}$ & $p$ \\
\hline Day of measurement & -0.17 & 0.006 \\
Mean of 4 days before & -0.17 & 0.004 \\
Mean of 7 days before & -0.20 & 0.001 \\
Mean of 14 days before & -0.19 & 0.002 \\
Mean of 21 days before & -0.18 & 0.004 \\
\hline
\end{tabular}

*Partial regression coefficients adjusted for sex, age, body mass index and smoking.

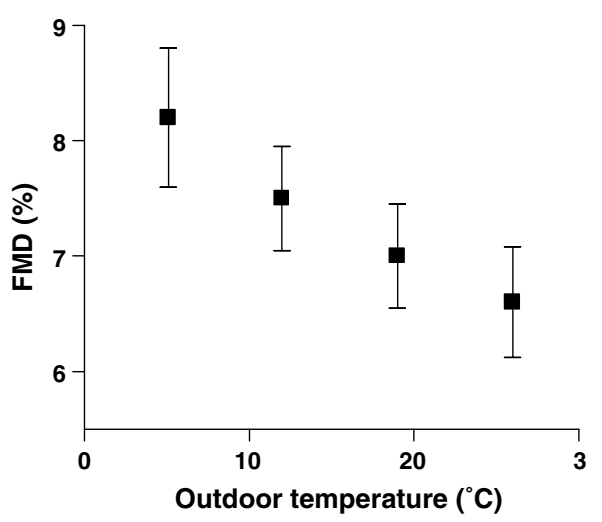

Figure 2. Flow-mediated vasodilatation as a function of maximal outdoor temperature. Mean flow-mediated vasodilatation $( \pm \mathrm{SE})$ by quartiles of temperature.

examination the odds were $58 \%(95 \% \mathrm{CI}$ : $4-141 \%$; $p=0.030$ ). Our findings were consistent when maximal temperatures were used instead of the daily average.

\section{Discussion}

The endothelium generates a variety of biological mediators, which influence the tone and structure of the blood vessel and determine the susceptibility of the vessel wall to atherogenesis. One of these mediators is nitric oxide, which is synthesized from the amino acid L-arginine via the action of the enzyme nitric oxide synthase. We showed that hot weather is associated with a decrease in endothelial function independent of age, smoking and other covariables.

Both endogenous mechanisms and exogenous factors might explain this relation. Indeed, hot weather may lead to dehydration and increased blood viscosity, which in turn might stimulate thrombogenesis, especially in predisposed patients with atherosclerosis. In addition, hot weather is also associated with an increase in the concentrations of ozone and small particulate matter in the air. Small dust particles carry many environmental pollutants, such as polyaromatic hydrocarbons and other chemicals produced by emissions from traffic and industry [12, 13]. Particles pass rapidly into the systemic circulation [14]. Ozone as well as particulate matter can induce cytokine production and systemic inflammation, which in turn may lead to endothelial dysfunction [15]. Because of its rural character, the Flemish Environment Agency did not monitor the concentration of these pollutants in the study area during the total course of the study.

From March 2002 to March 2003 we measured endothelial function in a random population sample, while we raised the hypothesis that endothelial function might be an intermediate factor contributing to the temperature-mediated increase in acute cardiovascular events on the basis of the observed excess mortality during the 2003 heat wave in France. Therefore, it is unlikely that the association between endothelial function and outdoor function could be influenced by observer bias.

Most epidemiological studies on temperature and mortality showed a ' $U$ ' or ' $J$ ' shape where mortality rises at extremes of cold or hot temperature $[1,2,16]$. We showed a linear decrease in endothelial function over the whole temperature range. The most likely explanation is that different mechanisms explain the increased cardiovascular mortality during cold vs. hot spells. Arterial thrombosis is promoted by the haemconcentration [17, 18] induced by cold, and coronary deaths could result from rupture of atheromatous plaques during hypertension and cold-induced coronary spasm [19].

The effect of high outdoor temperature on the endothelium is not only a 'fascinating hypothesis' for the epidemiologist but may have clinical implications. Studies in persons with risk factors or prevalent cardiovascular disease have demonstrated that endothelial dysfunction identifies patients at risk for future cardiovascular events [20,21]. Our subjects were randomly recruited from the population and were generally in good health. We speculate that in patients with pre-existing cardiovascular disease and endothelial dysfunction, the presently observed effects might be exaggerated and might more readily trigger cardiovascular complications. Lower endothelial function with advancing age has been a consistent finding in prior studies [22, 23]. The mechanisms remain uncertain but may relate to ageassociated increases in reactive oxygen species production and decrease in telomere length [24, 25].

Our findings are important because for the first time they suggest that endothelial dysfunction might be a plausible mechanism contributing to the temperature-mediated increase in acute cardiovascular events. This study also has implications for those studying endothelial function because temperature was not recognized as a potential confounding variable so far. 


\section{References}

1. Huynen MM, Martens P, Schram D, Weijenberg MP, Kunst AE. The impact of heat waves and cold spells on mortality rates in the Dutch population. Environ Health Perspect 2001; 109: 463-470.

2. Keatinge WR, Donaldson GC, Cordioli E, et al. Heat related mortality in warm and cold regions of Europe: Observational study. Br Med J 2000; 321: 670-673.

3. Alberdi JC, Diaz J, Montero JC, Miron I. Daily mortality in Madrid community 1986-1992: Relationship with meteorological variables. Eur J Epidemiol 1998; 14: $571-578$.

4. Mackenbach JP, Borst V, Schols JM. Heat-related mortality among nursing-home patients. Lancet 1997; 349: 1297-1298.

5. McGeehin MA, Mirabelli M. The potential impacts of climate variability and change on temperature-related morbidity and mortality in the United States. Environ Health Perspect 2001; 109: 185-189.

6. Nawrot T, Den Hond E, Thijs L, Staessen JA. Isolated systolic hypertension and the risk of vascular disease. Curr Hypertens Rep 2003; 5: 372-379.

7. Vita JA, Keaney JF. Endothelial function - A barometer for cardiovascular risk? Circulation 2002; 106: 640-642.

8. Faulx MD, Wright AT, Hoit BD. Detection of endothelial dysfunction with brachial artery ultrasound scanning. Am Heart J 2003; 145: 943-951.

9. Gokce N, Keaney JF Jr., Hunter LM, et al. Predictive value of noninvasively determined endothelial dysfunction for long-term cardiovascular events in patients with peripheral vascular disease. J Am Coll Cardiol 2003; 41: 1769-1775.

10. Gokce N, Holbrook M, Duffy SJ, et al. Effects of race and hypertension on flow-mediated and nitroglycerinmediated dilation of the brachial artery. Hypertension 2001; 38: 1349-1354.

11. Tounian P, Aggoun Y, Dubern B, et al. Presence of increased stiffness of the common carotid artery and endothelial dysfunction in severely obese children: A prospective study. Lancet 2001; 358: 1400-1404.

12. Oftedal B, Nafstad P, Magnus P, Bjorkly S, Skrondal A. Traffic related air pollution and acute hospital admission for respiratory diseases in Drammen, Norway 1995-2000. Eur J Epidemiol 2003; 18: 671-675.

13. Staessen JA, Nawrot T, Den Hond E, et al. Renal function, cytogenetic measurements and sexual development in adolescents in relation to environmental pollutants: A feasibility study of biomarkers. Lancet 2001; 357: 1660-1669.

14. Nemmar A, Hoet PH, Vanquickenborne B, et al. Passage of inhaled particles into the blood circulation in humans. Circulation 2002; 105: 411-414.
15. Nemmar A, Hoet PH, Dinsdale D, Vermylen J, Hoylaerts MF, Nemery B. Diesel exhaust particles in lung acutely enhance experimental peripheral thrombosis. Circulation 2003; 107: 1202-1208.

16. Pan WH, Li LA, Tsai MJ. Temperature extremes and mortality from coronary heart disease and cerebral infarction in elderly Chinese. Lancet 1995; 345: 353 355.

17. Donaldson GC, Robinson D, Allaway SL. An analysis of arterial disease mortality and BUPA health screening data in men, in relation to outdoor temperature. Clin Sci 1997; 92: 261-268.

18. Neild PJ, Syndercombe-Court D, Keatinge WR, Donaldson GC, Mattock M, Caunce M. Cold-induced increases in erythrocyte count, plasma cholesterol and plasma fibrinogen of elderly people without a comparable rise in protein C or factor X. Clin Sci 1994; 86: 43-48.

19. Mudge GH Jr., Grossman W, Mills RM Jr., Lesch M, Braunwald E. Reflex increase in coronary vascular resistance in patients with ischemic heart disease. $\mathrm{N}$ Engl J Med 1976; 295: 1333-1337.

20. Modena MG, Bonetti L, Coppi F, Bursi F, Rossi R. Prognostic role of reversible endothelial dysfunction in hypertensive postmenopausal women. J Am Coll Cardiol 2002; 40: 505-510.

21. Celermajer DS, Sorensen KE, Bull C, Robinson J, Deanfield JE. Endothelium-dependent dilation in the systemic arteries of asymptomatic subjects relates to coronary risk factors and their interaction. J Am Coll Cardiol 1994; 24: 1468-1174.

22. Benjamin EJ, Larson MG, Keyes MJ, et al. Clinical correlates and heritability of flow-mediated dilation in the community: The Framingham Heart Study. Circulation 2004; 109: 613-619.

23. Herrington DM, Fan L, Drum M, et al. Brachial flowmediated vasodilator responses in population-based research: Methods, reproducibility and effects of age, gender and baseline diameter. J Cardiovasc Risk 2001; 8: 319-328.

24. Nawrot T, Staessen J, Gardner J, Aviv A. Telomere length and possible link to $\mathrm{X}$ chromosome. Lancet 2004; 363: 507-510.

25. Minamino T, Komuro I. Role of telomere in endothelial dysfunction in atherosclerosis. Curr Opin Lipidol 2002; 13: 537-543.

Address for correspondence: Tim S. Nawrot, Studiecoördinatiecentrum, Laboratorium Hypertensie, Campus Gasthuisberg, Herestraat 49, B-3000 Leuven, Belgium.

E-mail: tim.nawrot@med.kuleuven.ac.be 